\title{
Early reperfusion with warm, polarizing adenosine-lidocaine cardioplegia improves functional recovery after 6 hours of cold static storage
}

\author{
Donna M. Rudd, MSc, and Geoffrey P. Dobson, $\mathrm{PhD}$
}

Objective: Rewarming and reanimating the donor heart from cold static storage predisposes the organ to injury and graft dysfunction. Our main aim was to investigate the effects of 5 minutes of continuous rewarming with a normokalemic, oxygenated, polarizing adenosine-lidocaine arrest solution after 6 hours of cold static storage $\left(4^{\circ} \mathrm{C}\right)$ in adenosine-lidocaine or Celsior (Genzyme Corp, Cambridge, Mass) solutions.

\begin{abstract}
Methods: Male Sprague-Dawley rats $(350-450 \mathrm{~g}, \mathrm{n}=40)$ were randomly assigned to one of 5 groups: (1) adenosine-lidocaine cold arrest with modified Krebs-Henseleit rewarming, (2) adenosine-lidocaine cold arrest with adenosine-lidocaine rewarming, (3) Celsior cold arrest with Celsior rewarming, (4) Celsior cold arrest with Krebs-Henseleit, and (5) Celsior cold arrest with adenosine-lidocaine arrest rewarming. Hearts were perfused in working mode, arrested $\left(37^{\circ} \mathrm{C}\right)$, removed and stored for 6 hours at $4^{\circ} \mathrm{C}$, reattached in Langendorff mode, and rewarmed for 5 minutes $\left(37^{\circ} \mathrm{C}\right)$. Hearts were switched to working mode, and function was compared with prestorage values. Myocardial oxygen consumption and effluent lactate and $\mathrm{pH}$ values were measured during rewarming and recovery.
\end{abstract}

Results: Cold adenosine-lidocaine hearts rewarmed with Krebs-Henseleit recovered $40 \%$ aortic flow and 58\% coronary flow at 60 minutes of reperfusion. Rewarming with adenosine-lidocaine arrest solution led to significantly higher aortic flow $(63 \%)$ and coronary flow $(77 \%)$ at 60 minutes. Cold Celsior hearts rewarmed with Celsior had 9 times higher effluent lactate values with acidosis $(\mathrm{pH}$ 6.5) during the last minute of rewarming compared with all groups, and this was associated with early myocardial, vascular, and electrical stunning. At 5 and 10 minutes of recovery, the aortic flow was 1.0 and $8 \mathrm{~mL} / \mathrm{min}$, respectively. If cold Celsior hearts were rewarmed with adenosine-lidocaine, they generated 18-fold higher aortic flow and 16-fold higher coronary flow at 5 minutes. At 60 minutes, cold Celsior with Celsior-rewarmed hearts recovered 35\% aortic flow and $50 \%$ coronary flow compared with $44 \%$ aortic flow and $67 \%$ coronary flow $(P<.05)$ for Celsior with adenosine-lidocaine-rewarmed hearts. Celsior with Krebs-Henseleit-rewarmed hearts recovered $39 \%$ aortic flow and $51 \%$ coronary flow and were not significantly different from Celsior-rewarmed hearts. The myocardial oxygen consumption in the last minute of rewarming was 1.6 times higher for cold adenosine-lidocaine hearts rewarmed with adenosine-lidocaine compared with cold Celsior and Celsior hearts (19 vs $12 \mu \mathrm{mol} \mathrm{O}_{2} / \mathrm{min} / \mathrm{g}$ dry weight) along with low lactate values and no acidosis.

Conclusions: Rewarming the rat heart after cold static storage in polarizing adenosine-lidocaine arrest solution resulted in significantly higher aortic flow, coronary flow, and cardiac output compared with that seen after Krebs-Henseleit or Celsior rewarming. Rewarming cold Celsior hearts with adenosine-lidocaine solution reduced stunning. Adenosine-lidocaine cardioplegia might offer a new reperfusion strategy after cold static storage. (J Thorac Cardiovasc Surg 2011;141:1044-55)

Over the past 3 decades, the design of organ-preservation solutions has been based on 3 fundamental principles: (1) hyperkalemic arrest, (2) a suitable cold ischemic milieu to

From the Heart Research Laboratory, Department of Physiology and Pharmacology, James Cook University, Townsville, Queensland, Australia.

Supported by Australian National Health and Medical Research grant 540409.

Disclosures: Authors have nothing to disclose with regard to commercial support.

Received for publication Feb 5, 2010; revisions received March 16, 2010; accepted for publication April 4, 2010; available ahead of print July 5, 2010.

Address for reprints: Geoffrey P. Dobson, PhD, Heart Research Laboratory, Department of Physiology and Pharmacology, James Cook University, Townsville, Queensland 4811 Australia (E-mail: geoffrey.dobson@jcu.edu.au).

$0022-5223 / \$ 36.00$

Copyright (c) 2011 by The American Association for Thoracic Surgery doi: 10.1016/j.jtcvs.2010.04.040 maintain cell viability, and (3) protection from reperfusion injury. ${ }^{1-3}$ Hyperkalemic arrest depolarizes the cell membrane and places the heart in a highly vulnerable state, which can damage the myocardium and coronary microvasculature, leading to cellular $\mathrm{Ca}^{2+}$ loading, vasoconstriction and spasm, arrhythmias, and atrial and ventricular stunning. ${ }^{2-7}$ The untoward effects of high potassium are further exacerbated by global ischemia during cold static storage temperatures and by regional ischemia during rewarming and implantation, ${ }^{6}$ which together can contribute to graft injury and rejection. ${ }^{8}$

Over the last 10 years, our laboratory has focused on developing a normokalemic nondepolarizing cardioplegia 


$$
\begin{aligned}
& \text { Abbreviations and Acronyms } \\
& \qquad \begin{array}{ll}
\text { AF } & =\text { aortic flow } \\
\text { AL } & =\text { adenosine-lidocaine } \\
\text { ATP } & =\text { adenosine triphosphate } \\
\text { CF } & =\text { coronary flow } \\
\mathrm{KH} & =\text { Krebs-Henseleit } \\
\mathrm{MVO}_{2} & =\text { myocardial oxygen consumption }
\end{array}
\end{aligned}
$$

in the rat model that clamps the membrane potential closer to its resting voltage of around $-83 \mathrm{mV}$ by using adenosine and lidocaine (AL) as the active arrest composition. ${ }^{5-7}$ The idea was borrowed from natural hibernators and places the heart in a more natural state of suspended animation. ${ }^{9}$ In 2009 , the concept of polarized arrest was extended to orthotopic heart transplantation, ${ }^{6}$ and we showed in the isolated rat heart that AL was versatile as a preservation solution at both cold static storage $\left(4^{\circ} \mathrm{C}\right)$ and warmer intermittent perfusion $\left(28^{\circ} \mathrm{C}-\right.$ $30^{\circ} \mathrm{C}$ ) compared with Celsior solution (Genzyme Corp, Cambridge, Mass). ${ }^{6}$ In 2010, we further showed that AL cardioplegia at $32^{\circ} \mathrm{C}$ to $33^{\circ} \mathrm{C}$ demonstrated superior arrest and functional recovery profiles when the membrane potential was maintained around the resting cell voltage compared with pathological hyperpolarized hypokalemic $(<3 \mathrm{mmol} /$ $\mathrm{L})$ or depolarized hyperkalemic $\left(10\right.$ and $\left.16 \mathrm{mmol} / \mathrm{L} \mathrm{K}^{+}\right)$arrest states. ${ }^{7}$

The basic electrophysiology behind polarized versus depolarized arrest is that at resting diastolic membrane potentials, there are fewer open membrane channels, pores, and exchangers compared with those at depolarized states. $^{5,7,10,11}$ The adverse effects of using depolarizing potassium at $-50 \mathrm{mV}$ is that many voltage-dependent membrane channels $\left(\mathrm{Ca}^{2+}, \mathrm{Na}^{+}\right.$window current, and $\left.\mathrm{K}^{+}\right)$, pores, and exchangers $\left(\mathrm{Na}^{+} / \mathrm{H}^{+}\right.$and $\left.\mathrm{Na}^{+} / \mathrm{Ca}^{2+}\right)$ are activated, which, over time, can lead to $\mathrm{Na}^{+}$and $\mathrm{Ca}^{2+}$ loading and cell injury and possibly death. ${ }^{5,10,11}$ Maintaining a polarized membrane also appears to have anti-inflammatory properties. Ward and colleagues ${ }^{12}$ showed, for example, that emigrated neutrophils, after adhering to rat ventricular myocytes, caused an immediate membrane depolarization, which contributed to an inflammatory-linked generation of arrhythmias, tissue injury, and contractile dysfunction. However, when they held the cell membrane potential around the natural resting polarized state, they demonstrated reduced damage from inflammatory attack. Despite showing $\mathrm{AL}$ cardioprotection during polarized arrest and recovery, ${ }^{5-7}$ we have not investigated the benefits of warm $\mathrm{AL}$ cardioplegia for reperfusion immediately after cold static storage before normothermic spontaneous reanimation. The aim of the present study was to investigate the effects of early reperfusion after 6 hours of cold static storage by using normokalemic, oxygenated, polarizing $\mathrm{AL}$ arrest solution in the isolated rat heart. Hearts preserved for 6 hours at $4^{\circ} \mathrm{C}$ in $\mathrm{AL}$ cardioplegia or Celsior were reperfused and rewarmed for 5 minutes with either KrebsHenseleit (KH; polarizing nonarrest), $\mathrm{AL}$ (polarizing arrest), or Celsior (depolarizing arrest) solutions before being switched to working mode to compare their functional recoveries.

\section{MATERIALS AND METHODS \\ Animals}

Male Sprague-Dawley rats $(350-450 \mathrm{~g}, \mathrm{n}=40)$ were obtained from James Cook University's breeding colony. Animals were fed ad libitum and housed in a 12-hour light/dark cycle. On the day of the experiment, rats were anesthetized with an intraperitoneal injection of thiopentone sodium (Thiobarb, $60 \mathrm{mg} / \mathrm{kg}$ body weight; Jurox, Rutherford, Australia), and the hearts were rapidly excised, as described by Dobson and Jones. ${ }^{5}$ Rats were handled in compliance with James Cook University Guidelines (ethics approval no. A1084) and the "Guide for the care and use of laboratory animals" from the National Institutes of Health (publication no. 85-23, revised 1985, and PHS publication 1996). Adenosine (A9251, >99\% purity) and all other chemicals were obtained from Sigma Chemical Company (Castle Hill, New South Wales, Australia). Lidocaine hydrochloride was purchased as a $2 \%$ solution (ilium) from the local Pharmaceutical Supplies (Lyppard, Queensland, Australia).

\section{Composition of Modified KH Perfusion Buffer}

The modified $\mathrm{KH}$ buffer contained $10 \mathrm{mmol} / \mathrm{L}$ glucose, $117 \mathrm{mmol} / \mathrm{L}$ $\mathrm{NaCl}, 5.9 \mathrm{mmol} / \mathrm{L} \mathrm{KCl}, 25 \mathrm{mmol} / \mathrm{L} \mathrm{NaHCO} 3,1.2 \mathrm{mmol} / \mathrm{L} \mathrm{NaH} \mathrm{NO}_{4}$, $1.12 \mathrm{mmol} / \mathrm{L} \mathrm{CaCl}$ (free $\left.\mathrm{Ca}^{2+}=1.07 \mathrm{mmol} / \mathrm{L}\right)$, and $0.512 \mathrm{mmol} / \mathrm{L}$ $\mathrm{MgCl}_{2}$ (free $\mathrm{Mg}^{2+}=0.5 \mathrm{mmol} / \mathrm{L}$ ) at $\mathrm{pH} 7.4$ and $37^{\circ} \mathrm{C}$. The perfusion buffer was filtered by using a $1-\mu \mathrm{m}$ membrane and then bubbled vigorously with $95 \% \mathrm{O}_{2} / 5 \% \mathrm{CO}_{2}$ to achieve a $\mathrm{PO}_{2}$ value of greater than $600 \mathrm{~mm} \mathrm{Hg}$. The perfusion buffer was not recirculated.

\section{Arrest Solutions for Normothermic Induction and Cold Static Storage}

AL solution. The AL cardioplegia contained $200 \mu \mathrm{mol} / \mathrm{L}$ adenosine plus $500 \mu \mathrm{mol} / \mathrm{L}$ lidocaine in $10 \mathrm{mmol} / \mathrm{L}$ glucose containing $\mathrm{KH}$ buffer (pH 7.7 at $37^{\circ} \mathrm{C}$ ), as described by Dobson and Jones. ${ }^{5}$ The solution was filtered with $0.2-\mu \mathrm{m}$ filters and maintained at $37^{\circ} \mathrm{C}$. The arrest solution was not actively bubbled with $95 \% \mathrm{O}_{2} / 5 \% \mathrm{CO}_{2}$, hence the higher $\mathrm{pH}$. The average $\mathrm{Po}_{2}$ value of the $\mathrm{AL}$ solution was $140 \mathrm{~mm} \mathrm{Hg}$, and the $\mathrm{PCO}_{2}$ value was 5 to $10 \mathrm{~mm} \mathrm{Hg}$.

Celsior solution. The Celsior solution contained $100 \mathrm{mmol} / \mathrm{L} \mathrm{NaOH}$, $15 \mathrm{mmol} / \mathrm{L} \mathrm{KCl}, 13 \mathrm{mmol} / \mathrm{L} \mathrm{MgCl} 2,0.25 \mathrm{mmol} / \mathrm{L} \mathrm{CaCl} 2,20 \mathrm{mmol} / \mathrm{L}$ glutamic acid, $80 \mathrm{mmol} / \mathrm{L}$ lactobionic acid, $30 \mathrm{mmol} / \mathrm{L}$ histidine, and $3 \mathrm{mmol} / \mathrm{L}$ glutathione at $\mathrm{pH} 7.3$. The solution was filtered with a $0.2-\mu \mathrm{m}$ filter, was not actively bubbled with $95 \% \mathrm{O}_{2} / 5 \% \mathrm{CO}_{2}$, and had an average $\mathrm{Po}_{2}$ value of $149 \mathrm{~mm} \mathrm{Hg}$.

\section{Arrest Solutions for 5-Minute Warm Reperfusion After Cold Static Storage}

The AL and Celsior arrest solutions were the same as described above, except that they were actively bubbled with $95 \% \mathrm{O}_{2} / 5 \% \mathrm{CO}_{2}$ to achieve a $\mathrm{Po}_{2}$ value of greater than $600 \mathrm{~mm} \mathrm{Hg}$ and not recirculated. Nonarrest modified $\mathrm{KH}$ was identical to the above.

\section{Experimental Groups}

Rats were randomly assigned to one of 5 groups ( $n=8$ each group): (1) $\mathrm{AL}$ cold $\left(4^{\circ} \mathrm{C}\right)$ static storage plus 5 minutes of rewarming $\mathrm{KH}$ reperfusion, 


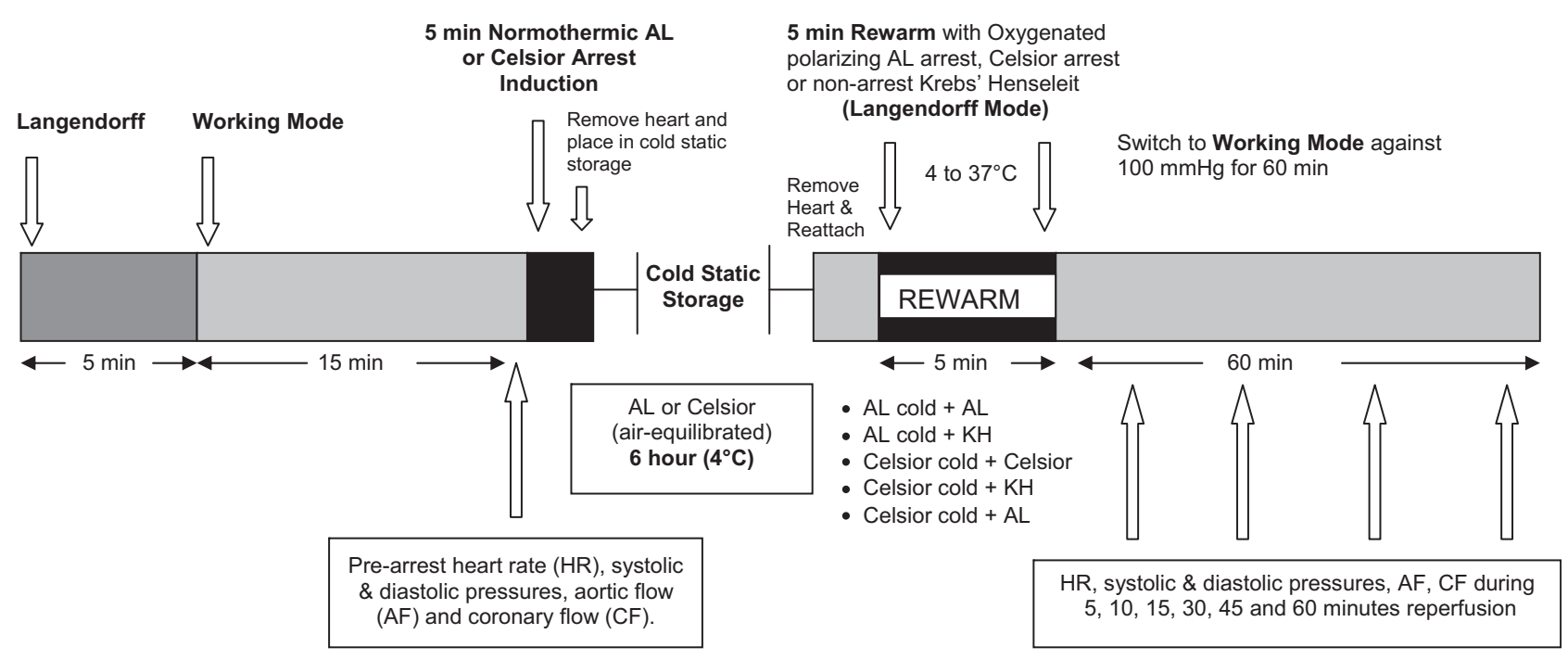

FIGURE 1. Experimental protocol. Isolated rat hearts were placed in cold static storage for 6 hours in (1) adenosine-lidocaine $(A L)$ polarizing cardioplegia or (2) Celsior depolarizing preservation solutions and continuously rewarmed in Langendorff mode for 5 minutes with different oxygenated reperfusion strategies (see the Materials and Methods section for details). $\mathrm{KH}$, Krebs-Henseleit solution.

(2) $\mathrm{AL}$ cold $\left(4^{\circ} \mathrm{C}\right)$ static storage plus 5 minutes of rewarming with $\mathrm{AL}$ arrest reperfusion, (3) Celsior cold $\left(4^{\circ} \mathrm{C}\right)$ static storage plus 5 minutes of rewarming Celsior arrest reperfusion, (4) Celsior cold $\left(4^{\circ} \mathrm{C}\right)$ static storage plus 5 minutes of rewarming $\mathrm{KH}$, and $(5)$ Celsior cold $\left(4^{\circ} \mathrm{C}\right)$ static storage plus 5 minutes of rewarming AL arrest reperfusion. After 5 minutes of rewarming, hearts were switched to working mode and reperfused with modified $\mathrm{KH}$ buffer for 60 minutes. Celsior rewarming was not studied with AL cold storage because Celsior solution was not designed as a normokalemic, normothermic reperfusion solution. ${ }^{13}$ In their early study, Menasche and associates ${ }^{13}$ arrested rat hearts with a hypothermic $\left(4^{\circ} \mathrm{C}\right)$ flush of Celsior solution, stored hearts for 5 hours at $4^{\circ} \mathrm{C}$, reattached the heart in Langendorff mode, and reperfused with $\mathrm{KH}$ solution for 60 minutes. Celsior reperfusion was included in the Celsior storage group because it was a simple extension of the storage condition differing only in temperature and oxygenation before switching to working mode reperfusion. Celsior cold storage has been reported to reduce injury to the heart in the transition from cold to warm reperfusion. ${ }^{13}$

\section{Langendorff and Working Rat Heart Preparation}

Hearts were rapidly removed from anesthetized rats and placed in icecold heparinized modified KH buffer. Details of heart preparation, attachment, and perfusion were described in Rudd and Dobson. ${ }^{6}$ Briefly, hearts were attached to a Langendorff apparatus and perfused at a pressure head of $90 \mathrm{~cm} \mathrm{H}_{2} \mathrm{O}(68 \mathrm{~mm} \mathrm{Hg})$. The pulmonary artery was not cannulated before arrest and detaching the heart for cold static storage to prevent vessel wall damage. The artery was cannulated during reattachment of the heart after cold static storage for collection of coronary venous effluent and $\mathrm{O}_{2}$ consumption measurements (see below). For working mode operation, a small incision was made in the left atrial appendage, and a cannula was inserted and sutured. The heart was then switched from the Langendorff apparatus to working mode by switching the supply of perfusate from the aorta to the left atrial cannula at a hydrostatic pressure of $10 \mathrm{~cm} \mathrm{H}_{2} \mathrm{O}$ (preload) and an afterload of $100 \mathrm{~cm} \mathrm{H}_{2} \mathrm{O}(76 \mathrm{~mm} \mathrm{Hg})$. Hearts were stabilized for 15 minutes, and prearrest data were recorded before converting back to Langendorff mode before inducing normothermic arrest. In working mode the perfusion buffer was not recirculated.

Heart rate, aortic pressure, coronary flow (CF), and aortic flow (AF) were measured before and after 6 hours of arrest and cold static storage (Figure 1). Aortic pressure was measured continuously with a pressure transducer (ADI Instruments, Sydney, Australia) coupled to a MacLab 2e
(ADI Instruments). Systolic and diastolic pressures and heart rates were calculated from the pressure trace by using MacLab software. Arterial and venous perfusate $\mathrm{PO}_{2}$ and $\mathrm{PCO}_{2}$ values and $\mathrm{pH}$ were measured with a Bayer 865 blood gas machine (Siemens Diagnostics, Melbourne, Australia). $\mathrm{CF}$ and $\mathrm{AF}$ were measured in volumetric cylinders. $\mathrm{CF}$ before cold static storage was measured not directly from the pulmonary artery but from pulmonary artery drainage with a volumetric flask placed below the heart. No pacing or cardiac massage was used during the reanimation phase in working mode. The working heart model was chosen because it is ejecting fluid against a pressure head and performs pressure-bydistance work in contrast to the nonejecting Langendorff model, which performs no physical work. The key to isolated rat heart perfusions is a clean apparatus that was maintained by flushing weekly with $5 \mathrm{~L}$ of $3 \%$ hydrogen peroxide and $1 \%$ glacial acetic acid solution followed by a thorough rinse with $10 \mathrm{~L}$ of 18 megaohm water. The initial criteria for exclusion of working hearts during the 15 -minute equilibration period were a heart rate of less than 200 beats/min, a systolic pressure of less than $100 \mathrm{~mm}$ $\mathrm{Hg}$, and a CF of less than $10 \mathrm{~mL} / \mathrm{min}$.

\section{Cold Static Storage $\left(4^{\circ} \mathrm{C}\right)$ and Early Reperfusion}

The method of cold static storage for rat hearts has been described by Rudd and Dobson. ${ }^{6}$ Briefly, hearts were arrested at a constant pressure head of $90 \mathrm{~cm} \mathrm{H}_{2} \mathrm{O}(68 \mathrm{~mm} \mathrm{Hg})$ by using AL cardioplegia or Celsior solution for 5 minutes $(50-100 \mathrm{~mL})$ at $37^{\circ} \mathrm{C}$ for their respective groups. Hearts were gently removed from the apparatus and placed in a $50-\mathrm{mL}$ tube containing their respective air-equilibrated preservation solutions, and the sealed tube was immersed in the water bath set at $4^{\circ} \mathrm{C}$ for a period of 6 hours (Figure 1). After 6 hours of cold static storage, the hearts were immediately reattached to the perfusion apparatus, and fresh warm oxygenated solutions ( $\mathrm{AL}, \mathrm{KH}$, or Celsior) were used to reperfuse the heart in nonworking Langendorff mode at a pressure head of $90 \mathrm{~cm} \mathrm{H}_{2} \mathrm{O}(68 \mathrm{~mm} \mathrm{Hg})$ for 5 minutes (Figure 1); the heart's surface temperature was $28^{\circ} \mathrm{C}$ to $32^{\circ} \mathrm{C}$. The warm reperfusion period of 5 minutes was chosen because the first few minutes appear to be the most critical for optimal cardioprotection after ischemia. ${ }^{14}$ The heart's surface temperature was measured with a Cole-Parmer thermistor-thermometer (8402-20; Cole-Parmer Instrument Co, Vernon Hills, IIl), which was tucked under the left auricle. Hearts were then switched to working mode and reperfused for 60 minutes at $37^{\circ} \mathrm{C}$ by using oxygenated glucose containing $\mathrm{KH}$ solution at $\mathrm{pH}$ 7.4. Hearts were allowed to 
spontaneously return function during reperfusion and were not electrically assisted if function did not return. Functional data $\mathrm{AF}, \mathrm{CF}$, heart rate, and systolic and diastolic pressures) were measured after 15 minutes of equilibration immediately before arrest and at 5-, 10-, 15-, 30-, 45-, and 60-minute time points during the 60 minutes of reperfusion. This data were compared with the baseline (prearrest) data for each group.

\section{Calculation of Myocardial Oxygen Consumption}

Myocardial oxygen consumption $\left(\mathrm{MVO}_{2}\right.$; in micromoles of oxygen per minute per gram of dry weight heart) was calculated by using equation 1 , as follows ${ }^{5}$ :

$$
\begin{aligned}
\mathrm{MVO}_{2}= & \frac{\left(\mathrm{paO}_{2}-\mathrm{pvO}_{2}\right)}{(B p-\mathrm{V} p)} \times \frac{\alpha \mathrm{O}_{2}}{22.40} \times \frac{\text { Coronary Flow }}{\text { gm dry wt }} \times 1000 \\
= & \frac{\mathrm{mmHg}}{\mathrm{mmHg}} \times \frac{\mathrm{ml} / \mathrm{ml}}{\mathrm{ml} / \mathrm{mol}} \times \frac{\mathrm{ml} / \mathrm{min}}{\text { gm dry wt }} \times 1000
\end{aligned}
$$

where $\mathrm{PaO}_{2}$ and $\mathrm{PvO}_{2}$ are the partial pressures of oxygen (in millimeters of mercury) in the arterial and venous perfusion lines. $B p$ is the barometric pressure $\left(760 \mathrm{~mm} \mathrm{Hg}\right.$ ), and $V p$ is the water vapor pressure at $37^{\circ} \mathrm{C}$ $(47.1 \mathrm{~mm} \mathrm{Hg})$. The molar volume for oxygen at standard temperature and pressure was $22.40 \mathrm{~mL} / \mathrm{millimole} .^{5} \alpha \mathrm{O}_{2}$ is the Bunsen solubility coefficient defined as that volume of oxygen gas dissolved in one milliliter of solution at a specified temperature reduced to standard temperature and pressure $\left(\mathrm{O}^{\circ} \mathrm{C}, 760 \mathrm{~mm} \mathrm{Hg}\right)$; the $\alpha \mathrm{O}_{2}$ at $37^{\circ} \mathrm{C}$ for human plasma is $0.024 \mathrm{~mL} / \mathrm{mL} .{ }^{5}$ Coronary venous effluent was measured in milliliters per minute, and heart weight was expressed as grams of dry weight. Total tissue water (as a percentage) was determined by the difference in wet weight and dry weight divided by wet weight and multiplied by 100 . Baseline or prearrest $\mathrm{MVO}_{2}$ values were not obtained because the pulmonary artery was not cannulated before placing the heart in cold static storage to avoid damage occurring to the vessel. In its place we used the average baseline normothermic $\mathrm{MVO}_{2}$ values from isolated rat hearts of the same age and weight measured in our laboratory. These prearrest $\mathrm{MVO}_{2}$ data were measured in the 2009 cold static storage study of Rudd and Dobson ${ }^{6}$ but were not included in that article. They are representative of the prearrest state in the present study because they were measured under identical conditions of equilibration, perfusion, and temperature. ${ }^{6}$

\section{Lactate Output During Warm Reperfusion}

Coronary effluent $(1.0-1.5 \mathrm{~mL})$ was collected in small 1.5-mL Eppendorf tubes during the last minute of the rewarming period and stored at $-20^{\circ} \mathrm{C}$ until analysis (approximately 2 weeks). Perfusate lactate values were analyzed with the Cobas Integra 800 by using a colorimetric kit purchased from Roche Diagnostics (Castle Hill, Australia). Output results were in millimoles per liter and converted to micromoles per minute per gram of dry weight by using effluent $\mathrm{CF}$ and heart weight as in equation 2, as follows:

$$
\begin{aligned}
\text { Lactate }(\mu \mathrm{mol} / \mathrm{min} / \mathrm{g} \text { dry wt }) & =\text { Lactate }(\mu \mathrm{mol} / \mathrm{mL}) \\
& \times \text { Coronary flow }(\mathrm{mL} / \mathrm{min}) \\
& \times 1 / \text { Heart weight }(\mathrm{g} \text { dry wt })^{-1}
\end{aligned}
$$

\section{Calculation of Total Adenosine Triphosphate Production During Warm Reperfusion}

Total ATP $(\mu \mathrm{mol} / \mathrm{g}$ dry weight heart $)=\mathrm{ATP}_{\text {aerobic }}+\mathrm{ATP}_{\text {anaerobic }}$

Adenosine triphosphate (ATP; aerobic) was defined as the total ATP produced by means of mitochondrial oxidative phosphorylation, assuming
$1.0 \mu \mathrm{mol}$ of $\mathrm{O}_{2}$ forms $6.0 \mu \mathrm{mol}$ of ATP, for a P:O ratio of 3.0, according to equation 4 , as follows:

$$
\begin{aligned}
\operatorname{ATP}(\text { aerobic }) & =\mathrm{MVO}_{2}\left(\mu \mathrm{mol} \mathrm{O}_{2} / \mathrm{min} / \mathrm{g} \text { dry weight }\right) \\
& \times 6\left(6 \mu \mathrm{mol} \mathrm{ATP} / \mu \mathrm{mol} \mathrm{O}_{2}\right)
\end{aligned}
$$

ATP (anaerobic) was defined as the ATP produced from anaerobic glycogenolytic metabolism, where $1 \mu \mathrm{mol}$ glucosyl unit from glycogen forms $2 \mu \mathrm{mol}$ of lactate with the formation of $3 \mu \mathrm{mol}$ of ATP. ATP (anaerobic) was calculated from lactate output by using equation 5 , as follows:

$$
\begin{aligned}
\text { ATP }(\text { anaerobic }) & =\text { Lactate }(\mu \mathrm{mol} / \mathrm{min} / \mathrm{g} \text { dry weight }) \\
& \times 3 / 2(3 \mu \mathrm{mol} \text { ATP } / 2 \mu \text { mol lactate })
\end{aligned}
$$

The assumption here is that ATP generated anaerobically was principally derived from endogenous heart glycogen. We believe the $3 \mathrm{ATP} / 2$ lactate stoichiometry is justified based on the high effluent lactate value and low $\mathrm{pH}(6.5)$ from one of the groups (see the Results section). If exogenous glucose was the principal anaerobic fuel, $2 \mu \mathrm{mol}$ of ATP per glucosyl unit would be formed for $2 \mu \mathrm{mol}$ of lactate because hexokinase (EC 2.7.1.1) phosphorylates glucose to glucose-6-phosphate requiring $1 \mu \mathrm{mol}$ of ATP. The lactate and $\mathrm{O}_{2}$ consumption measurements were taken during the last minute of the 5-minute rewarming period with the different oxygenated reperfusion solutions.

\section{Statistical Analysis}

All results are expressed as the mean \pm standard error of the mean. Oneway analysis of variance was used to compare rat weights, arrest times, and times to first beat and AF. Two-way analysis of variance with repeated measures was used to compare recovery variables (eg, $\mathrm{AF}$, systolic and diastolic pressures, heart rate, and cardiac output [CO]) over multiple time points for the different treatment groups. One-way analysis of variance was used to compare recovery of variables at specific times points $(5,10,30,45$, and 60 minutes) during reperfusion in working mode. Significance was then assessed by using Bonferroni and Dunnett 2-way post hoc tests. The $\alpha$ level of significance for all experiments was set at a $P$ value of less than .05 .

\section{RESULTS}

Functional properties before and after cold static storage are shown in Table 1 and Figures 2 and 3. During prearrest, there were no significant differences among the 5 groups in $\mathrm{AF}, \mathrm{CF}, \mathrm{CO}$, heart rate, developed pressures, or rate-pressure product (Table 1).

\section{Recovery of Aortic Flow}

At 5 minutes of reperfusion in working mode, the AL cold group with $\mathrm{KH}$ and $\mathrm{AL}$ rewarming recovered $13 \%$ and $25 \%$ of their prearrest values, respectively, and these increased to $21 \%$ and $42 \%$ at 10 minutes (Table 1 and Figure 2, A). In contrast, hearts preserved in cold Celsior and rewarmed with Celsior or $\mathrm{KH}$ each generated only $2 \%$ of prearrest $\mathrm{AF}$ at 5 minutes, respectively. However, when rewarmed with $\mathrm{AL}$, the $\mathrm{AF}$ increased 18-fold at 5 minutes (Table 1 and Figure 2, A). At 10 minutes, $\mathrm{AF}$ in the cold Celsior solution with Celsior and $\mathrm{KH}$ rewarming groups increased to $14 \%$ and $9 \%$ of prearrest values, respectively; however, these recoveries were still one third to one half of the value if rewarmed with AL. At 30 minutes, the cold AL group rewarmed with $\mathrm{KH}$ solution increased $\mathrm{AF}$ by around 1.9-fold and the AL rewarming group by about 1.4 -fold, after which the $\mathrm{AF}$ remained relatively stable (Table 1 and Figure $1, A$ ). 
TABLE 1. Functional parameters of isolated working rat hearts during different rewarming-reperfusion strategies after 6 hours of cold static storage in polarizing adenosine-lidocaine or depolarizing Celsior solutions (see the Materials and Methods section for details)

\begin{tabular}{|c|c|c|c|c|c|c|}
\hline \multirow[b]{2}{*}{ 6-h Arrest } & \multirow{2}{*}{$\begin{array}{c}\text { Cold Arrest }+ \text { Rewarming } \\
\text { Treatment }\end{array}$} & \multirow[b]{2}{*}{$\mathbf{n}$} & \multicolumn{2}{|c|}{ Aortic flow (mL/min) } & \multicolumn{2}{|c|}{ Coronary flow (mL/min) } \\
\hline & & & Value & $\% \mathbf{P A}$ & Value & $\% \mathbf{P A}$ \\
\hline \multirow[t]{7}{*}{ 15-min Prearrest } & AL 6-h arrest & & & & & \\
\hline & + Krebs-Henseleit & 8 & $62 \pm 5$ & & $24 \pm 2$ & \\
\hline & $+\mathrm{AL}$ cardioplegia & 8 & $65 \pm 2$ & & $22 \pm 2$ & \\
\hline & Celsior 6-h arrest & & & & & \\
\hline & + Celsior rewarming & 8 & $57 \pm 3$ & & $22 \pm 2$ & \\
\hline & + Krebs-Henseleit & 8 & $67 \pm 2$ & & $22 \pm 1$ & \\
\hline & $+\mathrm{AL}$ cardioplegia & 8 & $59 \pm 2$ & & $21 \pm 1$ & \\
\hline \multirow[t]{7}{*}{ 5-min Recovery } & AL 6-h arrest & & & & & \\
\hline & + Krebs-Henseleit & 8 & $8 \pm 2$ & 13 & $14 \pm 1$ & 58 \\
\hline & $+\mathrm{AL}$ cardioplegia & 8 & $16 \pm 5^{*}$ & $25^{*}$ & $8 \pm 3$ & 36 \\
\hline & Celsior 6-h arrest & & & & & \\
\hline & + Celsior rewarming & 8 & $1 \pm 1 \ddagger$ & $2 \ddagger$ & $2 \pm 2 \ddagger \S$ & $9 \ddagger, \S$ \\
\hline & + Krebs Henseleit & 8 & $1 \pm 1$ & 2 & $12 \pm 1$ & 55 \\
\hline & $+\mathrm{AL}$ cardioplegia & 8 & $18 \pm 4 \|$ & $31 \|$ & $16 \pm 1$ & 76 \\
\hline \multirow[t]{7}{*}{ 10-min Recovery } & AL 6-h arrest & & & & & \\
\hline & + Krebs-Henseleit & 8 & $13 \pm 3$ & 21 & $14 \pm 1$ & 58 \\
\hline & + AL cardioplegia & 8 & $27 \pm 3 *$ & $42 *$ & $17 \pm 1 *$ & $77^{*}$ \\
\hline & Celsior 6-h arrest & & & & & \\
\hline & + Celsior rewarming & 8 & $8 \pm 6$ & 14 & $9 \pm 4 \ddagger$ & $41 \ddagger$ \\
\hline & + Krebs-Henseleit & 8 & $6 \pm 3$ & 9 & $12 \pm 1$ & 55 \\
\hline & + AL cardioplegia & 8 & $16 \pm 3 \|$ & $27 \|$ & $15 \pm 1$ & 71 \\
\hline \multirow[t]{7}{*}{ 30-min Recovery } & AL 6-h arrest & & & & & \\
\hline & + Krebs-Henseleit & 8 & $25 \pm 1$ & 40 & $14 \pm 1$ & 58 \\
\hline & + AL cardioplegia & 8 & $39 \pm 2^{*} \uparrow$ & $60 * \dagger$ & $16 \pm 1 *$ & $73 *$ \\
\hline & Celsior 6-h arrest & & & & & \\
\hline & + Celsior rewarming & 8 & $18 \pm 7 \ddagger$ & $32 \ddagger$ & $11 \pm 2$ & 50 \\
\hline & + Krebs-Henseleit & 8 & $23 \pm 4$ & 34 & $13 \pm 1$ & 59 \\
\hline & $+\mathrm{AL}$ cardioplegia & 8 & $25 \pm 3 \|$ & $42 \|$ & $14 \pm 1$ & 67 \\
\hline \multirow[t]{7}{*}{ 60-min Recovery } & AL 6-h arrest & & & & & \\
\hline & + Krebs-Henseleit & 8 & $25 \pm 1$ & 40 & $14 \pm 1$ & 58 \\
\hline & + AL cardioplegia & 8 & $41 \pm 2^{*} \uparrow$ & $63^{*} \dagger$ & $17 \pm 1^{*}$ & $77^{*}$ \\
\hline & Celsior 6-h arrest & & & & & \\
\hline & + Celsior rewarming & 8 & $20 \pm 7$ & 35 & $11 \pm 2$ & 50 \\
\hline & +Krebs-Henseleit & 8 & $26 \pm 5$ & 39 & $12 \pm 1$ & 51 \\
\hline & + AL cardioplegia & 8 & $26 \pm 3$ & 44 & $14 \pm 1$ & 67 \\
\hline
\end{tabular}

$\overline{A L}$, Adenosine-lidocaine. *AL (cold storage) with AL (rewarming) and Celsior (cold storage) with Celsior (rewarming), $P<.05$. †AL (cold storage) with AL (rewarming) and AL (cold storage) with Krebs -Henseleit (rewarming), $P<.05$. †Celsior (cold storage) with Celsior (rewarming) and Celsior (cold storage) with AL (rewarming), $P<.05$. $\S$ Celsior (cold storage) with Celsior (rewarming) and Celsior (cold storage) with Krebs -Henseleit (rewarming), $P<.05$. \|Celsior (cold storage) with AL (rewarming) and Celsior (cold storage) with Krebs -Henseleit (rewarming), $P<.05$.

\section{Recovery of Coronary Flow}

There was a rapid spontaneous return of $\mathrm{CF}$ in the cold $\mathrm{AL}$ groups rewarmed with $\mathrm{KH}$ and $\mathrm{AL}$ cardioplegia, with 58\% and $36 \%$ of prearrest values recovered at 5 minutes (Table 1 and Figure 2, $B$ ). However, the $\mathrm{KH}$ rewarming group did not increase $\mathrm{CF}$ further at 10,30, and 60 minutes of reperfusion. The cold AL with AL rewarming increased CF over 2-fold at 10 minutes compared with 5 minutes and stabilized at 30 and 60 minutes of reperfusion (Figure 2, B). In direct contrast to all other groups at 5 minutes, the cold Celsior with Celsior rewarming recovered only $9 \%$ of prearrest $\mathrm{CF}$. However, rewarming cold Celsior with $\mathrm{KH}$ or $\mathrm{AL}$ arrest solution led to significantly higher $55 \%$ and $76 \%$ recovery of $\mathrm{AF}$ at $5 \mathrm{~min}-$ utes (Table 1). At 10 minutes, the cold Celsior with Celsior rewarming increased $\mathrm{CF}$ from 2 to $9 \mathrm{~mL} / \mathrm{min}(41 \%$ baseline), and as with $\mathrm{KH}$ or AL rewarming, it did not increase further over the 60-minute reperfusion period (Table 1 and Figure 2, $B$ ).

\section{Recovery of Cardiac Output}

The cold AL group rewarmed with KH and AL cardioplegia returned $27 \%$ and $28 \%$ of prearrest cardiac output $(\mathrm{CO})$, respectively, at 5 minutes, whereas $\mathrm{CO}$ in the $\mathrm{KH}$ group did not increase further at 10 minutes, and $\mathrm{AL}$ rewarming increased it 1.8 -fold ( $51 \%$ of prearrest value). At 30 and 60 minutes, cold $\mathrm{AL}$ with $\mathrm{KH}$ rewarming increased $\mathrm{CO}$ to 


\begin{tabular}{|c|c|c|c|c|c|c|}
\hline \multicolumn{2}{|c|}{ Cardiac output $(\mathrm{mL} / \mathrm{min})$} & \multicolumn{2}{|c|}{ Heart rate (beats/min) } & \multirow{2}{*}{$\begin{array}{c}\text { Systolic pressure } \\
(\mathrm{mm} \mathrm{Hg})\end{array}$} & \multirow{2}{*}{$\begin{array}{l}\text { Diastolic pressure } \\
(\mathrm{mm} \mathrm{Hg})\end{array}$} & \multirow{2}{*}{$\begin{array}{c}\text { Rate-pressure product } \\
\text { (beats/mm Hg/min) }\end{array}$} \\
\hline Value & $\% \mathbf{P A}$ & Value & $\% \mathbf{P A}$ & & & \\
\hline $86 \pm 4$ & & $285 \pm 12$ & & $127 \pm 2$ & $60 \pm 0$ & $36,216 \pm 1692$ \\
\hline $87 \pm 3$ & & $282 \pm 7$ & & $124 \pm 2$ & $60 \pm 0$ & $35,064 \pm 1018$ \\
\hline $79 \pm 5$ & & $282 \pm 17$ & & $124 \pm 4$ & $60 \pm 0$ & $34,880 \pm 1511$ \\
\hline $90 \pm 2$ & & $284 \pm 6$ & & $130 \pm 0$ & $60 \pm 0$ & $36,969 \pm 810$ \\
\hline $80 \pm 2$ & & $280 \pm 10$ & & $128 \pm 1$ & $60 \pm 0$ & $35,613 \pm 1038$ \\
\hline $23 \pm 3$ & 27 & $228 \pm 8$ & 80 & $98 \pm 5$ & $66 \pm 4$ & $22,410 \pm 1579$ \\
\hline $24 \pm 7^{*}$ & $28^{*}$ & $109 \pm 32 \dagger$ & $39 \dagger$ & $71 \pm 20^{*}$ & $36 \pm 10 \dagger$ & $9706 \pm 3905^{*, \dagger}$ \\
\hline $3 \pm 3 \ddagger$ & $4 \ddagger$ & $38 \pm 26 \pm \S$ & $13 \ddagger \S$ & $26 \pm 18 \ddagger \S$ & $15 \pm 9 \ddagger \S$ & $3051 \pm 3216 \ddagger$ \\
\hline $13 \pm 2$ & 14 & $178 \pm 17$ & 63 & $87 \pm 4$ & $62 \pm 4$ & $15,863 \pm 2106$ \\
\hline $34 \pm 5$ & 43 & $197 \pm 19$ & 70 & $126 \pm 5$ & $60 \pm 1 \|$ & $24,774 \pm 2382$ \\
\hline $27 \pm 3$ & 31 & $242 \pm 15$ & 85 & $98 \pm 4$ & $66 \pm 4$ & $23,844 \pm 1890$ \\
\hline $44 \pm 3 * \dagger$ & $51^{*}+\dagger$ & $239 \pm 7$ & 85 & $118 \pm 2^{*}$ & $62 \pm 1^{*}$ & $28,038 \pm 821^{*}$ \\
\hline $17 \pm 9 \ddagger$ & $22 \ddagger$ & $157 \pm 71$ & 56 & $60 \pm 23 \ddagger$ & $38 \pm 14 \ddagger \S$ & $15,378 \pm 7221$ \\
\hline $18 \pm 4$ & 20 & $195 \pm 15$ & 69 & $96 \pm 4$ & $67 \pm 2$ & $18,858 \pm 1857$ \\
\hline $31 \pm 4$ & 39 & $217 \pm 14$ & 78 & $109 \pm 4$ & $66 \pm 1 \|$ & $23,598 \pm 1413$ \\
\hline $38 \pm 2$ & 44 & $286 \pm 15$ & 100 & $108 \pm 2$ & $68 \pm 1$ & $30,663 \pm 1438$ \\
\hline $55 \pm 3 *$ & $63 *$ & $277 \pm 9$ & 98 & $114 \pm 3^{*}$ & $63 \pm 2$ & $31,498 \pm 531$ \\
\hline $29 \pm 8$ & 37 & $228 \pm 43$ & 81 & $89 \pm 15$ & $59 \pm 9$ & $23,153 \pm 4970$ \\
\hline $36 \pm 5$ & 40 & $243 \pm 14$ & 86 & $109 \pm 4$ & $68 \pm 1$ & $26,401 \pm 1257$ \\
\hline $39 \pm 3$ & 49 & $261 \pm 16$ & 94 & $113 \pm 3$ & $64 \pm 2$ & $29,039 \pm 1072$ \\
\hline $39 \pm 1$ & 45 & $290 \pm 13$ & 102 & $105 \pm 3$ & $68 \pm 1$ & $30,265 \pm 1018$ \\
\hline $57 \pm 2^{*} \dagger$ & $66^{*}+\dagger$ & $284 \pm 8$ & 101 & $114 \pm 3^{*}$ & $62 \pm 1$ & $32,661 \pm 955^{*}$ \\
\hline $31 \pm 9$ & 39 & $238 \pm 46$ & 84 & $88 \pm 15 \ddagger$ & $60 \pm 9$ & $22,147 \pm 4874$ \\
\hline $38 \pm 6$ & 42 & $274 \pm 9$ & 96 & $106 \pm 3$ & $67 \pm 2$ & $28,581 \pm 986$ \\
\hline $40 \pm 3$ & 50 & $272 \pm 14$ & 97 & $113 \pm 3$ & $64 \pm 2$ & $30,021 \pm 991$ \\
\hline
\end{tabular}

$44 \%$ and $45 \%$ of prearrest values, respectively, whereas the $\mathrm{AL}$ rewarming strategy increased from $51 \%$ (10 minutes) to $63 \%$ and $66 \%$ of prearrest $\mathrm{CO}$ at 30 and 60 minutes of reperfusion. Because in the isolated working rat heart preparation $\mathrm{CO}$ is the sum of $\mathrm{AF}$ and $\mathrm{CF}$, the $\mathrm{CO}$ reflects the changes in $\mathrm{AF}$ and $\mathrm{CF}$. A point of emphasis is that cold Celsior hearts rewarmed with Celsior returned only $4 \%$ and $22 \% \mathrm{CO}$ at 5 and 10 minutes of reperfusion. At 30 minutes, the $\mathrm{CO}$ for this group increased nearly 2 -fold $(37 \%$ of prearrest value) and did not increase further at 60 minutes $(39 \%$ of prearrest value). In contrast, if cold Celsior hearts were rewarmed with $\mathrm{AL}$ cardioplegia, the return of $\mathrm{CO}$ was more rapid and significantly higher (up to 11 times) at 5 minutes compared with Celsior and $\mathrm{KH}$ rewarming (Table 1). At 10 minutes, the cold Celsior hearts with AL rewarming returned a CO of $39 \%$ of prearrest value, $49 \%$ of prearrest value at 30 minutes, and $50 \%$ of prearrest value at $60 \mathrm{~min}$ utes of reperfusion (Table 1).

\section{Recovery of Heart Rate}

At 5 minutes after switching from Langendorff rewarming to working mode, the cold AL group with $\mathrm{KH}$ rewarming or AL rewarming spontaneously returned a heart rate of 228 and 109 beats/min, respectively (Table 1 and Figure 2,C). The higher rate for the KH rewarming group at 5 minutes was significant and was due to them already beating in Langendorff mode. After 10 minutes, there was no significant difference between the $\mathrm{KH}$ or $\mathrm{AL}$ rewarming strategies (242 vs 239 beats/min). At 30 minutes, both rewarming groups increased their heart rates by around $17 \%$ and an additional $3 \%$ at 60 minutes (Table 1 ). There were no significant differences between these 2 groups from 10 to 

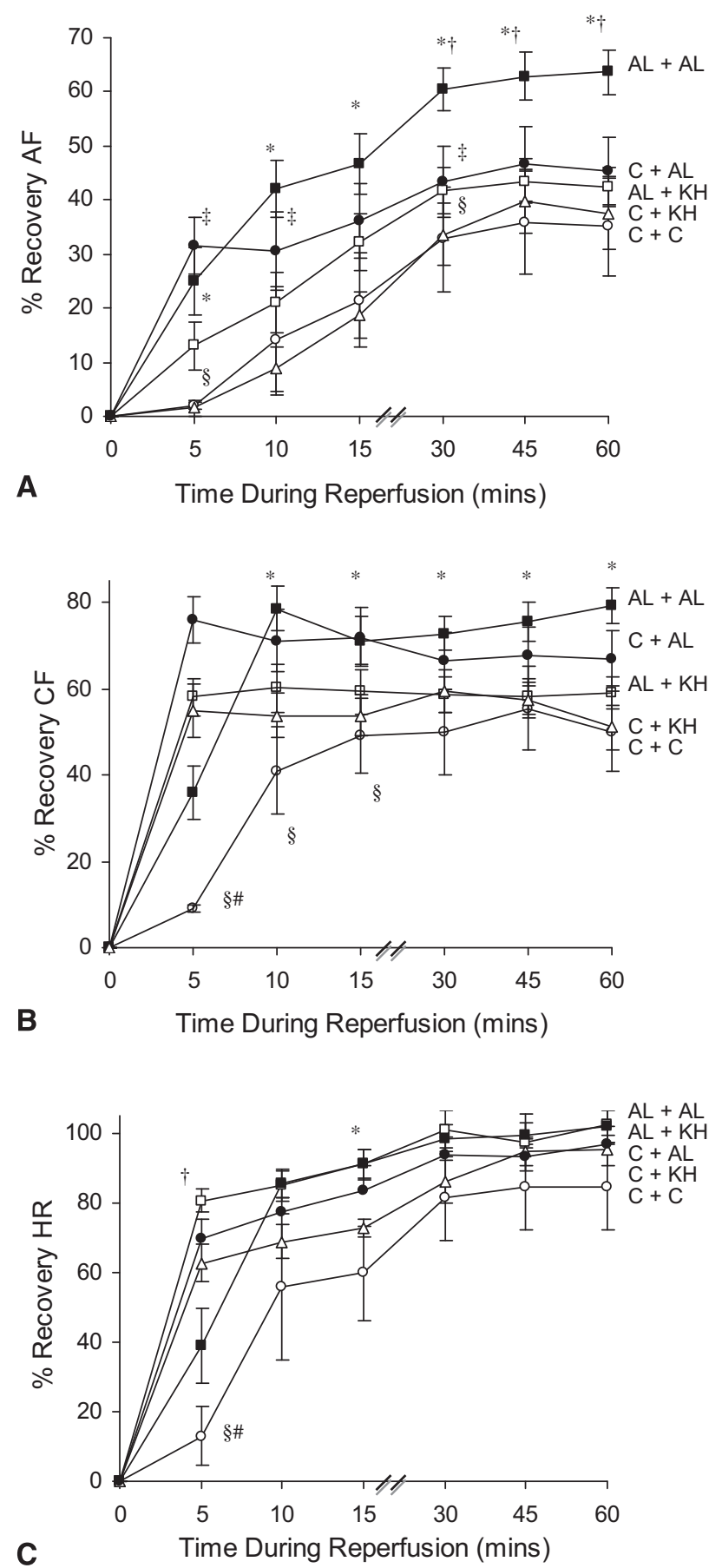

FIGURE 2. A, Percentage recovery of aortic flow $(A F)$ during 60 minutes of reperfusion in working mode immediately after 5 minutes of different oxygenated continuous reperfusion strategies in Langendorff mode. The 5 groups were as follows: (1) adenosine-lidocaine ( $A L$; cold) with KrebsHenseleit $(K H)$ rewarming (open squares); (2) AL (cold) with AL rewarming (solid squares); (3) Celsior ( $C$; cold) with Celsior rewarming (open circles); (4) Celsior (cold) with KH rewarming (open triangles), and (5) Celsior (cold) with AL rewarming (solid circles). B, Percentage recovery of coronary flow $(C F)$ during 60 minutes of reperfusion in working mode. C, Percentage recovery of heart rate $(H R)$ during 60 minutes of reperfusion in working mode. Significance $(P<.05)$ for panels A, B, and C was
60 minutes of reperfusion (Table 1 and Figure 2,C). In contrast, the heart rate for the cold Celsior hearts rewarmed with Celsior was 38 beats/min at 5 minutes $(13 \%$ of prearrest value), and this poor return was dramatically improved if cold Celsior hearts were rewarmed with $\mathrm{KH}$ or AL arrest solution; the heart rate rapidly and spontaneously increased from 38 beats/min to 178 to 197 beats/min for $\mathrm{KH}$ and $\mathrm{AL}$ rewarming, respectively ( $63 \%$ to $70 \%$ of baseline value). As with the cold AL group, there were no significant differences between rewarming with $\mathrm{KH}$ or AL cardioplegia in return of heart rate for the cold Celsior group, although the AL rewarming group had $7 \%$ to $12 \%$ higher values at 5,10 , and 30 minutes (Table 1 and Figure 2, C).

\section{Recovery of Systolic and Diastolic Pressures}

The developed pressures for the different groups followed similar patterns to those described for AFs. The cold Celsior group rewarmed with Celsior failed to generate sufficiently high pressures at 5 or 10 minutes compared with all other groups, and these were reflected in lower rate-pressure products at the different reperfusion times (Table 1). At 10 minutes, the cold Celsior with Celsior rewarming group could only generate a systolic/diastolic pressure of $60 / 38 \mathrm{~mm}$ $\mathrm{Hg}$. At 30 minutes, the systolic/diastolic pressures were $89 / 59 \mathrm{~mm} \mathrm{Hg}$, respectively, and at 60 minutes, they were $88 / 60 \mathrm{~mm} \mathrm{Hg}$ (Table 1). Interestingly, a full return of diastolic pressure occurred for this Celsior group at 30 minutes of reperfusion; however, the highest return of systolic pressure was only $70 \%$ of prearrest value (Table 1 ). The lower developed pressures for the cold Celsior with Celsior rewarming group were also reflected in lower rate-pressure products at the different reperfusion times (Table 1). The rate-pressure product is often used as a predictor of $\mathrm{MVO}_{2}$ value under different contractile states in experimental and clinical studies. Total tissue water for the cold AL with $\mathrm{KH}$ or with $\mathrm{AL}$ rewarming groups were $88 \% \pm$ $0.5 \%$ and $89 \% \pm 1 \%$, respectively. Total tissue water for cold Celsior with Celsior rewarming was $86 \% \pm 2 \%$, for Celsior with $\mathrm{KH}$ rewarming was $88 \% \pm 0.4 \%$, and for Celsior with AL rewarming was $87 \% \pm 0.4 \%(P<.05)$.

\section{$\mathrm{MVO}_{2}$ Value}

The mean value for the prearrest $\mathrm{MVO}_{2}$ in working mode was $37.6 \pm 0.8 \mu \mathrm{mol} \mathrm{O} / 2 / \mathrm{min} / \mathrm{g}$ dry weight $(\mathrm{n}=48$, see the Materials and Methods section). At the end of the rewarming phase, the $\mathrm{MVO}_{2}$ values for the cold AL preservation groups

as follows: *AL (cold) with AL (rewarming) and Celsior (cold) with Celsior (rewarming); † AL (cold) with AL (rewarming) and AL (cold) with KH (rewarming); $\S$ Celsior (cold) with Celsior (rewarming) and Celsior (cold) with AL (rewarming); \#Celsior (cold) with Celsior (rewarming) and Celsior (cold) with $\mathrm{KH}$ (rewarming); $\ddagger$ Celsior (cold) with AL (rewarming) and Celsior (cold) with KH (rewarming). 

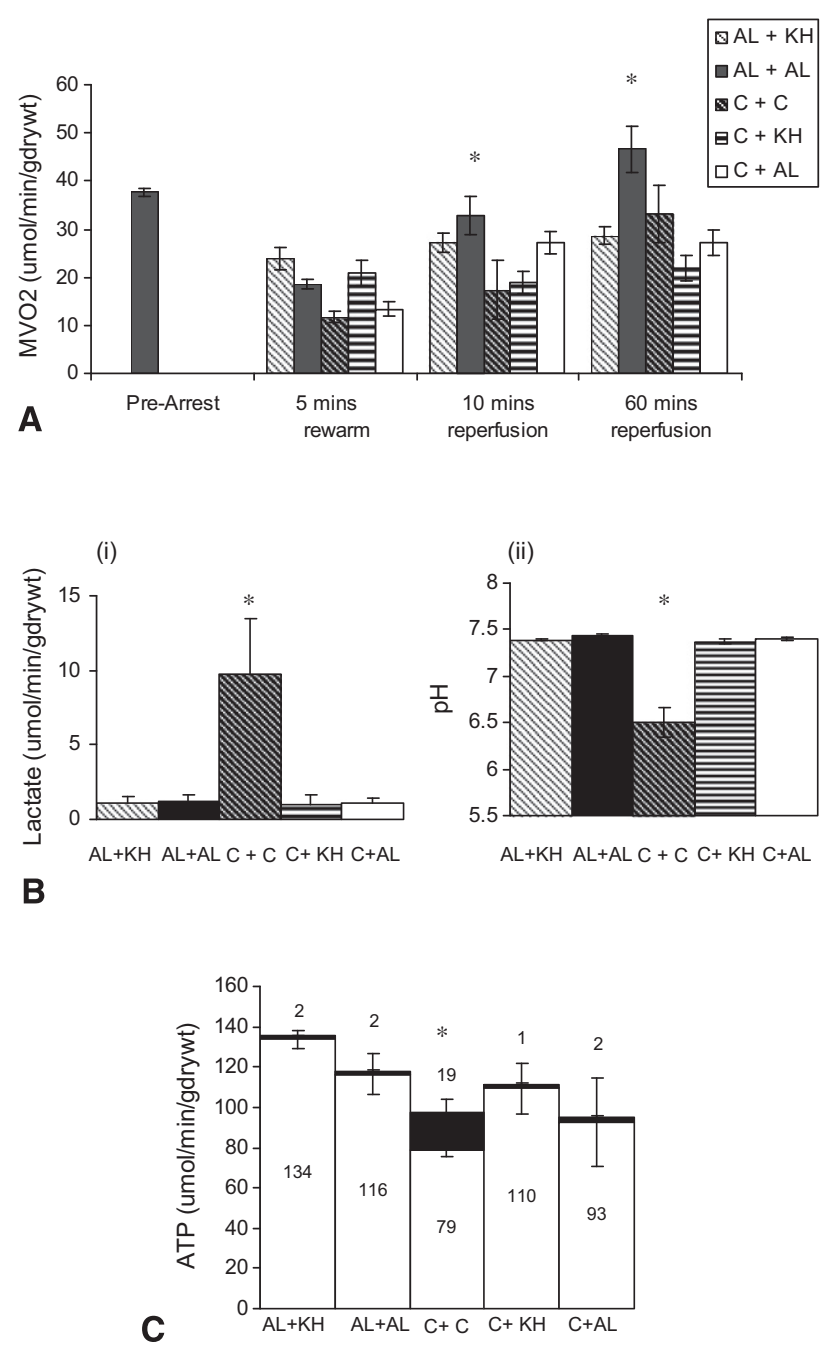

FIGURE 3. A, Myocardial oxygen consumption $\left(\mathrm{MVO}_{2}\right)$ values for the 5 different groups during the 5-minute rewarming period in Langendorff mode and at 10 and 60 minutes of reperfusion in working mode. The prearrest $\mathrm{MVO}_{2}$ value was a mean from 48 hearts taken from Rudd and Dobson ${ }^{6}$ (see the Materials and Methods section for details). Significance $(P<.05)$ was as follows: *adenosine-lidocaine ( $A L$; cold) with AL (rewarming) and Celsior $(C$; cold) with Celsior (rewarming); †AL (cold) with AL (rewarming) and AL (cold) with Krebs-Henseleit ( $K H$; rewarming). B $(i)$, Lactate output measured in the last minute of the 5-minute rewarming period in the different groups immediately before switching the heart from Langendorff mode to working mode. Significance $(P<.05)$ was as follows: *Celsior (cold) with Celsior (rewarming) was significantly higher than any other group. B (ii), Effluent pH measured in the last minute of the 5-minute rewarming period in the different groups immediately before switching the heart from Langendorff mode to working mode. Significance $(P<.05)$ was as follows: *Celsior (cold) with Celsior (rewarming) was significantly lower than any other group. $\mathrm{C}$, Adenosine triphosphate $(A T P)$ production in the last minute of the 5-minute rewarming period calculated from oxygen consumption and lactate production (see the Materials and Methods for equations). The white vertical bars represent the aerobic component to total ATP generation/replenishment, and the dark sections represent the anaerobic component in micromoles of ATP per minute per gram of dry weight. Significance $(P<.05)$ was as follows: *Celsior (cold) with Celsior (rewarm- in Langendorff mode with $\mathrm{KH}$ or AL arrest were $23.9 \pm 2.5$ and $18.6 \pm 1.0 \mu \mathrm{mol} \mathrm{O}_{2} / \mathrm{min} / \mathrm{g}$ dry weight, respectively (Figure 3, A). The $\mathrm{MVO}_{2}$ values for the cold Celsior group rewarmed with Celsior, $\mathrm{KH}$, or $\mathrm{AL}$ arrest were $11.7 \pm 1.2$, $20.9 \pm 2.7$, and $13.4 \pm 1.5 \mu \mathrm{mol} \mathrm{O}_{2} / \mathrm{min} / \mathrm{g}$ dry weight, respectively (Figure $3, A$ ). The coronary effluent flows in the final minute for the cold $\mathrm{AL}$ (KH and $\mathrm{AL}$ rewarming) groups were $12.8 \pm 0.9$ and $13.6 \pm 0.4 \mathrm{~mL}$, respectively, and those for the cold Celsior (Celsior, $\mathrm{KH}$, and $\mathrm{AL}$ rewarming) groups were $11.0 \pm 0.8,12.2 \pm 0.6$, and $11.2 \pm 0.9 \mathrm{~mL}$, respectively. During reperfusion in working mode at 10 and 60 minutes, the $\mathrm{MVO}_{2}$ values for the cold $\mathrm{AL}$ group reperfused with $\mathrm{KH}$ was $27.1 \pm 1.9$ and $28.7 \pm 1.8 \mu \mathrm{mol} \mathrm{O}_{2} / \mathrm{min} / \mathrm{g}$ dry weight, and that for the cold AL with AL rewarming group was slightly higher at 10 minutes $(32.7 \pm 4 \mu \mathrm{mol} \mathrm{O} 2 / \mathrm{min} / \mathrm{g}$ dry weight) and 1.6 times higher at 60 minutes $(46.6 \pm 4.9$ $\mu \mathrm{mol} \mathrm{O}_{2} / \mathrm{min} / \mathrm{g}$ dry weight; Figure $3, A$ ). The $\mathrm{MVO}_{2}$ values for the cold Celsior with Celsior rewarming group at 10 and 60 minutes of working mode were $17 \pm 6.0$ and $33.1 \pm 6.0$ $\mu \mathrm{mol} \mathrm{O}_{2} / \mathrm{min} / \mathrm{g}$ dry weight, respectively; those for the cold Celsior plus $\mathrm{KH}$ rewarming group were $19.0 \pm 2.3$ and $21.9 \pm 2.8 \mu \mathrm{mol} \mathrm{O} / \mathrm{min} / \mathrm{g}$ dry weight, respectively; and those for the cold Celsior plus AL rewarming group were $27.1 \pm 2.4$ and $27.3 \pm 2.7 \mu \mathrm{mol} \mathrm{O}_{2} / \mathrm{min} / \mathrm{g}$ dry weight, respectively (Figure 3, $A$ ).

\section{Lactate Output and ATP Production}

The lactate outputs for the cold AL group with $\mathrm{KH}$ or $\mathrm{AL}$ rewarming were $1.09 \pm 0.43$ and $1.13 \pm 0.51 \mu$ mol lactate/ $\mathrm{min} / \mathrm{g}$ dry weight (Figure $3, B, i$ ). In contrast, lactate production in the cold Celsior with Celsior rewarming group was nearly an order of magnitude higher at $9.79 \pm 3.7 \mu \mathrm{mol}$ lactate $/ \mathrm{min} / \mathrm{g}$ dry weight but not when rewarmed with $\mathrm{KH}$ or $\mathrm{AL}$, at which values were $0.98 \pm 0.64$ and $1.12 \pm 0.31$ $\mu \mathrm{mol} \mathrm{lactate} / \mathrm{min} / \mathrm{g}$ dry weight, respectively. Effluent $\mathrm{pH}$ values measured during the last minute of the 5-minute rewarming period are shown in Figure 3, B, ii. The $\mathrm{pH}$ in 4 of the 5 groups was around 7.37 to 7.43 , with the exception of the cold Celsior with Celsior rewarming group, which had nearly a 7.5-fold increase in hydrogen ion concentration (a decrease in $\mathrm{pH}$ from 7.4 to $6.5 \pm 0.16$ ).

The total ATP produced (aerobic and anaerobic) in the last minute of the 5-minute rewarming reperfusion period is shown in Figure 3, $C$. Values for the cold AL with $\mathrm{KH}$ or AL rewarming groups were $136 \pm 10$ and $118 \pm 5$ $\mu \mathrm{mol} \mathrm{ATP} / \mathrm{min} / \mathrm{g}$ dry weight, respectively, and for the cold Celsior with Celsior, $\mathrm{KH}$, or $\mathrm{AL}$ rewarming groups, the values were $98 \pm 12,111 \pm 21$, and $95 \pm 3 \mu \mathrm{mol}$ ATP/min/g dry weight, respectively (Figure $3, C$ ). Of the

ing) showed significantly higher ATP values from anaerobic glycogenolysis than any other group. 
total ATP produced, the anaerobic components for the cold $\mathrm{AL}$ with $\mathrm{KH}$ or AL rewarming groups were $1.5 \%$ and $1.7 \%$, and for the cold Celsior with Celsior, $\mathrm{KH}$, or AL rewarming groups, the percentages were $19.4 \%, 0.9 \%$, and $2.1 \%$ of the total ATP produced. The anaerobic production of ATP was significantly higher in the cold Celsior with Celsior rewarming group than in any other group and more than 10-fold higher than with cold Celsior reanimated with $\mathrm{AL}$ arrest solution.

\section{DISCUSSION}

Transferring the donor heart from a cold depolarizing storage environment to a warm environment for arousal and implantation predisposes the myocardium, vascular endothelium, and electrical conduction system to instability, which can contribute to graft injury and possible rejection. $^{1-3}$ Our study focused on the effect of rewarming donor hearts with polarizing and depolarizing reperfusion solutions after 6 hours of cold static storage. We report that rewarming the heart with oxygenated, polarizing $\mathrm{AL}$ arrest solution significantly increased AFs and CFs and developed pressures compared with $\mathrm{KH}$ rewarming alone. In addition, rewarming cold depolarizing Celsior hearts with AL arrest solution significantly increased reliance on aerobic versus anaerobic metabolism, with nearly an order of magnitude lower lactate values and no acidosis and faster times to higher spontaneous flows compared with those hearts rewarmed with depolarizing Celsior solution. Polarizing AL cardioplegia might have clinical significance to reduce the different facets of stunning during cold-to-warm transitions in heart transplantation and cardiac surgery.

\section{Rewarming With Polarizing AL Solution After Cold Static Storage}

Hearts stored for 6 hours at $4^{\circ} \mathrm{C}$ in cold AL arrest solution and rewarmed with $\mathrm{AL}$ recovered 1.6 times the $\mathrm{AF}, 1.2$ times the $\mathrm{CF}$, and 1.5 times the $\mathrm{CO}$ than hearts rewarmed with $\mathrm{KH}$ alone (AL vehicle) at 60 minutes of reperfusion (Table 1). The cold Celsior rewarmed with Celsior group was suboptimal, and its slow and poor recovery was partially reversed with $\mathrm{KH}$ or AL rewarming strategies (Figure 2, A and $B$ ). It was concluded that rewarming the depolarized or polarized $4^{\circ} \mathrm{C}$ hearts in $\mathrm{AL}$, oxygenated, polarized arrest solution resulted in less ischemia-reperfusion injury (Table 1 and Figures 2 and 3). Interestingly, recovery of heart rate from cold hearts was not significantly different between AL and $\mathrm{KH}$ rewarming (Table 1), indicating that polarizing normokalemic conditions per se without AL provided equivalent protection of the cardiac pacemaker and possibly the conduction system. However, the AL rewarming group consistently showed $7 \%$ to $12 \%$ higher heart rates at 5,10 , and 30 minutes than seen with $\mathrm{KH}$ rewarming alone (Table 1 and Figure 2, C).

\section{Effect of 5 Minutes of AL Warm Reperfusion on $\mathrm{MVO}_{2}$ Values}

In addition to improved working left ventricular and coronary function, rewarming cold AL hearts in nonworking Langendorff mode with AL arrest solution resulted in a relatively high $\mathrm{MVO}_{2}$ value. This high $\mathrm{MVO}_{2}$ value was associated with a 1.6-fold higher maintenance metabolism than for cold Celsior hearts rewarmed with either Celsior or $\mathrm{AL}$ (Figure 3, A). Because $\mathrm{MVO}_{2}$ values in the cold Celsior rewarmed with Celsior or AL group were not significantly different (11.72 vs $13.39 \mu \mathrm{mol} \mathrm{O}_{2} / \mathrm{min} / \mathrm{g}$ dry weight), the higher $\mathrm{MVO}_{2}$ value in the cold $\mathrm{AL}$ hearts rewarmed with $\mathrm{AL}$ is likely the result of the antecedent polarized AL arrest in cold static storage. In summary, a normokalemic, polarized AL storage environment combined with oxygenated AL rewarming reperfusion led to higher $\mathrm{MVO}_{2}$ values before switching to working mode, and this strategy appears to be more cardioprotective than all other treatment groups.

Another interesting finding during the last minute of rewarming was that the cold $\mathrm{AL}$ group with nonarrest $\mathrm{KH}$ alone (the vehicle of AL arrest solution) increased $\mathrm{MVO}_{2}$ values by only $30 \%(23.9 \pm 2.5 \mu \mathrm{mol} \mathrm{O} / 2 / \mathrm{min} / \mathrm{g}$ dry weight $)$ compared with AL rewarming alone (Figure 3, A). The $\mathrm{KH}$ group was a nonworking beating heart, and the higher $\mathrm{MVO}_{2}$ value was not due to higher CF because the effluent flow was $12.8 \mathrm{~mL} / \mathrm{min}$ at 5 minutes of rewarming compared with $13.6 \mathrm{~mL} / \mathrm{min}$ for AL-arrested hearts. We conclude that the extra $30 \% \mathrm{O}_{2}$ consumed in $\mathrm{KH}$-rewarmed hearts was largely derived from greater myocardial mitochondrial metabolism and $\mathrm{O}_{2}$ extraction and not from changes in coronary vascular resistance. Normally, cardiac maintenance or basal metabolism represents about $20 \%$ to $30 \%$ of the total energy flux ${ }^{15}$; however, the maintenance metabolism for cold arrest with $\mathrm{KH}$ rewarming appeared to be about $70 \%$ based on the contribution from AL arrest. As early as 1986, Allen and colleagues ${ }^{16}$ reported that the best myocardial recovery after global ischemia in dogs occurred when the heart consumed oxygen in excess of basal demands; our data would support this observation. Further studies are required during this critical rewarming/reperfusion period after cold static storage.

\section{Possible Reasons for the High Maintenance Metabolism During Rewarming}

In 1997, Lawton and coworkers ${ }^{17}$ reported a higher $\mathrm{MVO}_{2}$ value in isolated rabbit hearts during early reperfusion from 30 minutes of global arrest in hyperpolarizing pinacidil compared with depolarizing St Thomas Hospital solution. No postarrest functional differences were found between the 2 groups. Lawton and coworkers suggested that the higher $\mathrm{MVO}_{2}$ value after hyperpolarized arrest might be related to reparative processes or to a higher oxygen debt generated during ischemia. In our study the higher $\mathrm{MVO}_{2}$ value in cold AL hearts with AL rewarming does 
not appear to be related to repayment of oxygen debt because there was no excess lactate efflux or no metabolic acidosis (pH 7.4; Figure 3, B). Nor does the higher $\mathrm{MVO}_{2}$ appear to arise from reparative $\mathrm{O}_{2}$-consuming processes of viable myocytes because polarizing AL cardioplegia and rewarming showed superior functional recoveries compared with those of any other group (Figure 2). The higher $\mathrm{MVO}_{2}$ value during rewarming polarized arrest is more likely linked to improved mitochondrial oxidative replenishment of ATP to support a new maintenance steady-state metabolism. This new steady state in cold AL and AL-rewarmed hearts we believe is a restorative response to the rewarming oxygenation challenge and not a reparative response to ischemia-reperfusion injury because the lactate value was low and the effluent $\mathrm{pH}$ was 7.4. Adenosine might have assisted in purine salvage and maintenance of the adenylate pools within the myocardium and in stabilizing ATP. ${ }^{18,19}$

Further experiments are required to test these rewarming hypotheses and to test the effect of different durations of reperfusion and doses of AL in crystalloid and blood during the early rewarming phase. It would also be of interest to measure $\mathrm{MVO}_{2}$ values during cold static storage and transition to normothermic conditions, continuing for the entire rewarming-reperfusion period. For logistical reasons, it is difficult to measure $\mathrm{MVO}_{2}$ values during cold static storage. Dobson and Jones ${ }^{5,9}$ calculated $\mathrm{MVO}_{2}$ values in Langendorff arrested rat hearts during 2-minute normothermic infusions of $\mathrm{AL}$ cardioplegia over a 4-hour arrest period and reported values of between 6 and $8 \mu \mathrm{mol} \mathrm{O}_{2} / \mathrm{min} / \mathrm{g}$ dry weight for coronary effluent perfusate flows of 10 to $14 \mathrm{~mL} / \mathrm{min}$. In the present study the AL-rewarmed/arrested hearts had $\mathrm{MVO}_{2}$ values 2.6 times this value for maintenance metabolism at 5 minutes of oxygenated reperfusion (Figure $3, A$ ).

\section{Effect of Rewarming With Polarized AL Arrest Solution and Possible Prevention of Stunning}

One of the most striking results was the effect of rewarming on stunning in the Celsior group. In cold Celsior hearts there was a significant delay in the spontaneous return of AFs and CFs (Figure 2, $A$ and $B$ ) and a delay in return of sinus rhythm. After switching to working mode, the heart rate was highly variable and significantly lower during early and late reperfusion in this group (Figure 2, C). These suboptimal outcomes are consistent with Celsior-related myocardial, vascular, and electrical stunning. Stunning is defined as the loss of postoperative contractility during reperfusion without cell death. ${ }^{20}$ These early functional deficits were not found if Celsior rewarming was replaced with a polarizing AL rewarming strategy (Table 1 and Figure 2, $A$ and $B$ ), which implicates depolarizing hyperkalemia as a possible cause. Stunning in Celsior hearts was also associated with significant 9-fold higher lactate efflux and significantly lower effluent $\mathrm{pH}(\mathrm{pH}$ 6.5) before switching to working mode (Figure 3, $B$ and $C$ ). The higher lactate efflux and acidic $\mathrm{pH}$ at the 5-minute rewarming period was not due changes in effluent CFs because they were $11.0 \mathrm{~mL} / \mathrm{min}$ versus $12.2 \mathrm{~mL} / \mathrm{min}$ for the cold Celsior with Celsior rewarming and cold Celsior with $\mathrm{KH}$ rewarming groups, respectively. The anaerobic production of ATP in the cold Celsior with Celsior rewarming group was also significantly higher than in any other group and more than 10-fold higher than in the cold Celsior rewarmed with AL arrest solution group. This result in Celsior hearts is significant because Neely and associates $^{21}$ showed in isolated rat hearts that the decrease in contractile force of ischemic hearts was also associated with increased tissue lactate values. ${ }^{22}$

In a human transplantation study using Celsior cold preservation, Wildhirt and colleagues ${ }^{23}$ also reported myocardial and possibly endothelial stunning. They reported greater inotropic support within the first 5 postoperative days in patients receiving the Celsior-preserved donor hearts and a significant correlation between longer ischemic times in the Celsior group and reduced CF reserve, implicating endothelial dysfunction. Endothelin and inducible nitric oxide synthase gene expression were significantly higher in the Celsior group. ${ }^{23}$ Ventricular stunning is common in postimplantation denervated donor hearts and a key contributor to early graft failure during the first 30 days after transplantation. ${ }^{24-26}$ In summary, cold Celsior hearts reperfused for 5 minutes at $37^{\circ} \mathrm{C}$ before reanimation with warm $\mathrm{AL}$ cardioplegia showed no stunning when compared with hearts rewarmed with Celsior arrest solution alone. The possible reasons for improved spontaneous return of function after normokalemic, polarizing, oxygenated AL rewarming arrest include (1) return of myocardial and coronary vascular membrane voltages to their normal operating limits, thereby reducing $\mathrm{Ca}^{2+}$ loading and stunning ${ }^{5,7,10}$; (2) favoring aerobic replenishment of ATP where there is no net hydrogen ion production and less reliance on anaerobic metabolism; and (3) possibly reduced production of oxygen-derived free radicals and other oxidants compared with hyperkalemic depolarized myocytes and activated endothelial cells during rewarming and reperfusion. ${ }^{27}$

\section{Clinical Significance}

During organ storage, rewarming, and implantation, the donor heart enters and emerges from a hostile, cold depolarizing environment where it is subjected to unnatural changes in cell membrane voltage and ionic and metabolic imbalances. In the early 1990s, Wheeldon and coworkers ${ }^{28}$ from the Papworth Hospital reported that some form of reperfusion was used $55 \%$ of the time in 92 transplantation centers worldwide, and most used intermittent doses of cold blood or cold hyperkalemic, oxygenated, depolarizing crystalloid cardioplegia during implantation followed by normothermic blood reperfusion. In 1996, Pradas and associates $^{29}$ showed in human transplantation that continuous warm reperfusion was technically feasible and appeared to 
provide improved myocardial protection. These reperfusion methods were largely translated from the extensive preclinical and clinical studies of Buckberg's group and Menasche's group after cardioplegic arrest ${ }^{16,30}$ and from which the more targeted concept of controlled reperfusion was developed. $^{22,31}$

The present study has added another new concept and possible strategy for rewarming and reperfusing the donor heart. The strategy is rewarming with normokalemic, oxygenated, polarizing AL arrest solution. Cold or warm hyperkalemic depolarizing cardioplegia, combined with the effects of ischemia, acidosis, and temperature shifts, predisposes the heart to electrical and mechanical instability during reperfusion, which can lead to postoperative stunning. ${ }^{5,18,29,32}$ In contrast, restoring the heart's cell membrane potentials to their normal operational limits within the myocardium, with intact transmural and regional ionic heterogeneities, might promote a more electrically and mechanical stable heart. The new AL cold-warm normokalemic reperfusion strategy might also find utility in portable perfusion apparatuses by using controlled, low-pressure infusions to preserve the human donor heart. ${ }^{33,34}$ In summary, evolving technologies to minimize damage during rewarming and implantation of donor hearts and other organs include the following: (1) temperature control, (2) hemodynamic control (unloaded nonworking mode), (3) pressure control, and (4) reperfusate control. ${ }^{1,3,22,35}$ We propose a fifth strategy, namely membrane voltage control with normokalemic polarizing strategies.

\section{Limitations of the Study and Future Directions}

The rat heart model of cold static storage and rewarming differs from heart transplantation in a number of ways. Although both rat and human hearts are empty and nonworking in the physical sense and are perfused through the coronary vessels after storage, the rat heart in working mode has preload and afterload that are preset during normothermic reperfusion. In contrast, during weaning off cardiopulmonary bypass, the preload and afterload of the human donor heart are dynamic variables in which preload is determined by a balance of blood volume between the patient and oxygenator and afterload is dependent on the status of peripheral vascular resistance and CO. However, the rat model is still clinically relevant because myocardial and coronary vascular injury does occur in the human graft during early rewarming and reperfusion. Future studies are required to include patch-clamp methods, voltage measurements, immunohistochemistry, and testing of the AL reperfusion strategy in larger animal models combined with myocardial and endothelial injury biomarkers, such as troponins; inflammatory and procoagulative indices; and potential markers of primary graft dysfunction, such as hypoxia-inducible factor and donor serum protein concentration of SMARCAL1
(SWI/SNF-related matrix-associated actin-dependent regulator of chromatin subfamily A-like protein 1). ${ }^{36}$

\section{CONCLUSIONS}

Early continuous reperfusion with warm, oxygenated, normokalemic polarizing AL cardioplegia improved spontaneous functional recovery after 6 hours of cold static storage in the isolated rat heart. Rewarming cold Celsior hearts with AL solution appeared to reduce myocardial and microvascular stunning. The normokalemic AL arrest and preservation solution might find utility during cold-to-warm wash transitions and implantation of donor hearts.

We thank Professor Jakob Vinten-Johansen for his comments on the manuscript.

\section{References}

1. Jahania MS, Sanchez JA, Narayan P, Lasley RD, Mentzer RM. Heart preservation for transplantation: principles and strategies. Ann Thorac Surg. 1999;68: 1983-7.

2. Parolari A, Rubini P, Cannata A, Bonati L, Alamanni F, Tremoli E, et al. Endothelial damage during myocardial preservation and storage. Ann Thorac Surg. 2002;73:682-90.

3. Stoica SC, Duwarakan K, Satchithananda K, Dunning J, Large SR. Two-decade analysis of cardiac storage for transplantation. Eur J Cardiothorac Surg. 2001;20: 792-8.

4. Ackemann J, Gross W, Mory M, Schaefer M, Gebhard M. Celsior versus custodial: early postischemic recovery after cardioplegia and ischemia at $5^{\circ} \mathrm{C}$. Ann Thorac Surg. 2002;74:522-9.

5. Dobson GP, Jones MW. Adenosine and lignocaine: a new concept in nondepolarising surgical arrest, protection and preservation. J Thorac Cardiovasc Surg. 2004;127:794-805.

6. Rudd DM, Dobson GP. Towards a new cold and warm non-depolarising, normokalemic arrest paradigm for orthotopic heart transplantation. J Thorac Cardiovasc Surg. 2009; 137:198-207.

7. Sloots K, Dobson GP. Normokalemic adenosine-lidocaine cardioplegia: importance of maintaining a polarized myocardium for optimal arrest and reanimation. J Thorac Cardiovasc Surg. 2010;139:1576-86.

8. Millington TM, Madsen JC. Innate immunity in heart transplantation. Curr Opin Organ Transplant. 2009;14:571-6.

9. Dobson GP. Organ arrest, protection and preservation: natural hibernation to cardiac surgery: a review. Comp Biochem Physiol B Biochem Mol Biol. 2004;139: 469-85.

10. Snabaitis AK, Shattock MJ, Chambers DJ. Comparison of polarized and depolarized arrest in the isolated rat heart for long-term preservation. Circulation. 1997; 96:3148-56.

11. Chambers DJ, Hearse DJ. Cardioplegia and surgical ischaemia. In: Sperelakis N, Kurachi Y, Terzic A, Cohen MV, eds. Heart physiology and pathophysiology. San Diego: Academic Press; 2001:887-926.

12. Ward CA, Bazzazi H, Clark RB, Nygren A, Giles WR. Actions of emigrated neutrophils on $\mathrm{Na}+$ and $\mathrm{K}+$ currents in rat ventricular myocytes. Prog Biophys Mol Biol. 2006;90:249-69.

13. Menasche P, Termingnon JL, Pradier F, Grousset C, Mouas C, Alberici G, et al. Experimental evaluation of Celsior, a new heart preservation solution. Eur J Cardiothorac Surg. 1994;8:207-13.

14. Piper HM, Abdallah Y, Schäfer C. The first minutes of reperfusion: a window of opportunity for cardioprotection. Cardiovasc Res. 2004;61:365-71.

15. Gibbs CL, Loiselle DS. Cardiac basal metabolism. Jpn J Physiol. 2001;51: 399-426.

16. Allen BS, Okamoto F, Buckberg GD, Leaf J, Bugyi H. Effects of "duration"” of reperfusate administration versus reperfusate "dose" on regional functional, biochemical, and histochemical recovery. J Thorac Cardiovasc Surg. 1986;92:594-604.

17. Lawton JS, Hsia PW, McClain LC, Maier GW, Damiano RJ. Myocardial oxygen consumption in the rabbit heart after ischemia. Hyperpolarized arrest with pinacidil versus depolarized hyperkalemic arrest. Circulation. 1997;96(suppl II): 247-52. 
18. Canyon SJ, Dobson GP. The effect of adenosine and lidocaine infusion on myocardial high energy phosphates and $\mathrm{pH}$ during regional ischemia in the rat model in vivo. Can J Physiol Pharmacol. 2006;84:903-12.

19. Schulz K, Duschek C, Lasley RD, Bünger R. Adenosine enhances cytosolic phosphorylation potential and ventricular contractility in stunned guinea pig heart: receptor-mediated and metabolic protection. J Appl Physiol. 2007;102:1202-13.

20. Braunwald E, Kloner RA. The stunned myocardium: prolonged, postischemic ventricular dysfunction. Circulation. 1982;66:1146-9.

21. Neely JR, Rovetto MJ, Whitmer JT, Morgan HE. Effects of ischemia on function and metabolism of the isolated working rat heart. Am J Physiol. 1973;225: 651-8.

22. Osaki S, Ishino K, Kotani Y, Honjo O, Suezawa T, Kanki K, et al. Resuscitation of non-beating donor hearts using continuous myocardial perfusion: the importance of controlled initial reperfusion. Ann Thorac Surg. 2006;81:2167-71.

23. Wildhirt SM, Weis M, Schulze C, Conrad N, Rieder G, Enders G, et al. Effects of Celsior and University of Wisconsin preservation solutions on hemodynamics and endothelial function after cardiac transplantation in humans: a single-center, prospective, randomized trial. Transpl Int. 2000;13(suppl 1):S203-11.

24. Kendall SW, Bittner HB, Peterseim DS, Campbell KA, Van Trigt P. Right ventricular function in the donor heart. Eur J Cardiothorac Surg. 1997;11:609-15.

25. Obadia JF, Janier M, Dayoub G, Piriou V, Chassignolle JF, Dureau G. Posttransplant primary heart dysfunction and myocardial stunning. J Cardiothorac Vasc Anesth. 1997;11:880-2.

26. Bittner HB, Chen EP, Biswas SS, Pr Van Trigt, Davis RD. Right ventricular dysfunction after cardiac transplantation: primarily related to status of donor heart. Ann Thorac Surg. 1999;68:1605-11.
27. Sellke FW, Boyle EM, Verrier ED. Endothelial Cell injury in cardiovascular surgery: the pathophysiology of vasomotor dysfunction. Ann Thorac Surg. 1996;62: 1222-8.

28. Wheeldon D, Sharples L, Wallwork J, English T. Donor heart preservation survey. J Heart Lung Transplant. 1992;11:986-93.

29. Pradas G, Cuenca J, Juffe A. Continuous warm reperfusion during heart transplantation. J Thorac Cardiovasc Surg. 1996;111:784-90.

30. Vinten-Johansen J, Nakanishi K. Postcardioplegia acute cardiac dysfunction and reperfusion injury. J Cardiothorac Vasc Anesth. 1993;7(suppl 2):6-18.

31. Beyersdorf $\mathrm{F}$. The use of controlled reperfusion strategies in cardiac surgery to minimize ischaemia/reperfusion damage. Cardiovasc Res. 2009;83:262-8.

32. Canyon SJ, Dobson GP. Protection against ventricular arrhythmias and cardiac death using adenosine and lidocaine during regional ischemia in the in vivo rat. Am J Physiol Heart Circ Physiol. 2004;287:H1286-95.

33. Hassanein WH, Zellos L, Tyrrell TA, Healey NA, Crittenden MD, Birjiniuk V, et al Continuous perfusion of donor hearts in the beating state extends preservation time and improves recovery of function. J Thorac Cardiovasc Surg. 1998;116:821-30.

34. Ozeki T, Kwon MH, Gu J, Collins MJ, Brassil J, Miller MBJ, et al. Heart preservation using continuous ex vivo perfusion improves viability and functional recovery. Circ J. 2007;71:153-9.

35. Bethea BT, Yuh DD, Conte JV, Baumgartner WA. Heart transplantation. In: Cohn LH, Edmunds LH Jr., eds. Cardiac surgery in the adult. 2nd ed. New York: McGraw-Hill; 2003:1427-60.

36. Aharinejad S, Andrukhova O, Gmeiner M, Thomas A, Aliabadi A, Zuckerman A et al. Donor serum SMARCAL1 concentrations predict primary graft dysfunction in cardiac transplantation. Circulation. 2009;120(suppl):S198-205. 